\title{
Evaluation of Alternative Techniques to Determine Pork Carcass Value ${ }^{1}$
}

\author{
J. T. Akridge*, B. W. Brorsen*, L. D. Whipker ${ }^{\dagger}$, \\ J. C. Forrest ${ }^{\ddagger}$, C. H. Kuei ${ }^{\ddagger}$, and A. P. Schinckel ${ }^{\ddagger}$ \\ Departments of *Agricultural Economics and ${ }^{*}$ Animal Sciences, \\ Purdue University, West Lafayette, IN 47907 and \\ †Agri Business Group, Inc., Indianapolis, IN 46268
}

\begin{abstract}
Three techniques for estimating the value of pork carcasses were evaluated: an optical probe, a real-time ultrasound scanner, and an electromagnetic scanner (EMSCAN). The ability of these techniques to predict carcass value was compared to the predictive ability of actual measures of backfat depth and longissimus muscle area taken with a ruler and a dot grid. Results indicated the EMSCAN model was the best predictor of carcass value. However, the optical probe, ultrasound, and the ruler/dot grid all provided information not contained in the EMSCAN model. The choice among ultrasound, the optical probe, and the ruler/dot grid depends on
\end{abstract}

how the carcass will be used. There is no significant difference between ultrasound and the ruler/dot grid or the optical probe and the ruler/ dot grid if the carcass is to be marketed in wholesale primal form, but the ruler/dot grid is superior if the ham and loin are to be sold as lean, boneless products. A model combining the EMSCAN and optical probe readings provided more accurate value predictions than either technique alone. A carcass value matrix for use in pricing pork carcasses was developed using readings from the optical probe. Carcass use has a substantial impact on value differences between fat and lean pigs.

\section{Key Words: Pigs, Composition, Electrical Conductivity,} Marketing Techniques, Probes, Ultrasound

\section{Introduction}

Current methods of pricing live pigs do not adequately recognize differences in pork carcass composition and quality. Thus, consumer tastes and preferences are not transmitted effectively to producers Ukerd and Cramer, 1970; Miller, 1987; Quaife, 1987). Most pigs in the United States are

\footnotetext{
${ }^{1}$ An earlier version of this paper was presented at the 1989 Annu. Mtg. of the Am. Agric. Economics Assoc., Baton Rouge, LA, August 1, 1989. Journal paper no. 12708, Purdue Univ. Agric. Exp. Sta.

${ }^{2}$ Lewis (1948), commenting on the research of Dowell and Engleman (1949), provided an excellent discussion of the practical problems associated with carcass-merit pricingseveral of which are reiterated in the Packers and Stockyards Administration report developed 35 yr later.

Received May 1, 1990.

Accepted July 19, 1981.
}

not marketed on a carcass-merit basis, which would reward producers of the lean, high-quality pork demanded by consumers. Furthermore, the systems used by packers only pay minimal differentials between fat and lean pigs (Kauffman, 1990).

The Packers and Stockyards Administration (USDA, 1984) identified several reasons for limited carcass-merit marketing. Among these were the subjective appraisal of carcass composition and quality by the packer and general confusion about carcass-merit pricing. Also, some techniques designed to provide objective carcass composition data have proven unreliable when installed in modern pork processing facilities (Kempster et al., 1985) ${ }^{2}$. The method of carcass evaluation must be accurate and objective if producers are to embrace carcass-merit pricing.

This paper compares the ability of three techniques, real-time ultrasound, the optical probe, and an electromagnetic scanner, to predict carcass value. The research extends previous work 
Table 1. Descriptive statistics for 90 carcass samples

\begin{tabular}{|c|c|c|c|c|}
\hline Variable & Mean & SD & Maximum & Minimum \\
\hline Hot carcass wt, kg & 78.55 & 6.11 & 93.44 & 66.68 \\
\hline $\begin{array}{l}\text { Chilled carcass wt, kg } \\
\text { Totgl carcass value, \$ }\end{array}$ & 77.60 & 6.05 & 91.08 & 63.96 \\
\hline $\begin{array}{l}\text { (wholesale) } \\
\text { Carcass value, } \$ / 100 \mathrm{~kg}\end{array}$ & 100.31 & 8.47 & 121.37 & 83.66 \\
\hline $\begin{array}{l}\text { Carcass value, } \$ / 100 \text { kg } \\
\text { (wholesale) } \\
\text { Total carcass value, } \$\end{array}$ & 127.68 & 3.94 & 137.65 & 118.63 \\
\hline $\begin{array}{l}\text { (ean boneless) } \\
\text { Carcass value, } \$ / 100 \mathrm{~kg}\end{array}$ & 103.21 & 10.96 & 130.38 & 79.46 \\
\hline $\begin{array}{l}\text { (aean boneless) } \\
\text { Backfat depth }\end{array}$ & 131.27 & 7.71 & 153.82 & 107.87 \\
\hline Ruler (10th rib), cm & 2.84 & .71 & 5.21 & 1.52 \\
\hline Optical probe (11th rib), $\mathrm{cm}$ & 3.26 & .74 & 5.70 & 1.70 \\
\hline Ultrasound (10th rib), cm & 2.80 & .65 & 4.39 & 1.60 \\
\hline Longissimus muscle measure & & & & \\
\hline Area-dot grid (10th rib), $\mathrm{cm}^{2}$ & 32.87 & 4.70 & 48.45 & 18.98 \\
\hline Depth-optical probe (11th rib), $\mathrm{cm}$ & $\mathbf{4 . 7 4}$ & .82 & 7.00 & 3.15 \\
\hline Area-ultrasound (10th rib), $\mathrm{cm}^{2}$ & 34.80 & 4.52 & 48.00 & 26.50 \\
\hline EMSCAN reading (H45) & 62.01 & 10.56 & 85.72 & 42.72 \\
\hline EMSCAN reading (A75E) & 3,424.71 & 605.89 & $5,279.71$ & 2,288.71 \\
\hline Carcass length, $\mathrm{cm}$ & 80.07 & 3.08 & 88.80 & 74.93 \\
\hline Hot carcass temperature, ${ }^{\circ} \mathrm{C}$ & $\mathbf{3 8 . 3 4}$ & 1.23 & 40.50 & 34.28 \\
\hline
\end{tabular}

by testing the ability of these techniques to measure carcass value. Non-nested hypotheses tests are used that provide a statistical test of the alternative models rather than simply comparing relative $R^{2}$ values.

\section{Materials and Methods}

The sample consisted of 90 pigs randomly selected from Indiana field buying stations. After slaughter, the backfat depth at the 10th rib, $5 \mathrm{~cm}$ off the midline, was measured with a ruler and a Aloka DX-210 real-time ultrasound scanner (Corometrics Medical Systems, Peachtree City, GA) (Forrest et al., 1989). Likewise, longissimus muscle area was measured at this same location with a dot grid and the ultrasound scanner. (Descriptive statistics for the data set are reported in Table 1).

Weight of the hot carcass and the carcass temperature were recorded. The temperature of the carcass affects the electromagnetic scanner (EMSCAN) readings. Although carcass temperature would be reasonably constant in a packing plant, such consistency was not possible in the laboratory because of variations in the time between slaughter and the EMSCAN measurements. The carcass length from the anterior edge of the first rib to the anterior edge of the aitch

\footnotetext{
${ }^{3}$ When estimated with these data, the $\mathrm{R}^{2}$ for the original Kuei et al. (1989) model was .8975. The $\mathrm{R}^{2}$ for our model, which employs two EMSCAN variables, was .8803 .
}

bone was measured. Lean composition of the carcass was then estimated with an electromagnetic scanner (Model HA-2, Meat Quality Inc., Springfield, IL.

The EMSCAN device measures electrical conductivity of the carcass at 64 equidistant intervals, providing an asymmetric bell-shaped curve (Kuei et al., 1989). The curve peaks when the entire muscle mass is in the electromagnetic field. The height and area of curve segments were defined in relation to the curve peak. The starting point (left end) of the curve was defined as 0 and the peak as 100 , effectively defining the $x$-axis range for each curve as 0 to 150 . Drawing on work by Kuei et al. (1989), two EMSCAN variables were used to predict carcass composition and ultimately value: the height of the curve $45 \%$ of the distance from the origin to the peak $\left(\mathrm{H}_{45}\right)$ and the area under the curve from a point $3 / 4$ of the distance between the curve's origin and its peak to the curve's endpoint (A75E). Kuei et al. (1989) found that the EMSCAN reading at the curve's peak was the best predictor of lean composition. However, the value of the lean varies considerably across the primal cuts and other commercial products. The two variables chosen for this model were the best predictors of lean content in hams and loins (Kuei et al., 1989). These two cuts account for the majority of the commercial value of a carcass ${ }^{3}$. The model using two EMSCAN variables was selected because there is longerterm interest in using the scanner to predict the composition of the ham and the loin while the carcass is intact. 
After an overnight chill at $2^{\circ} \mathrm{C}$, the depth of the backfat and the longissimus muscle, $7 \mathrm{~cm}$ off the midline between the 11 th and 12th ribs, was measured using an Anitech PG-100 Pork Grader Coptical probe; Anitech, Markham, Ontario, Canada). The right side of the carcass was subsequently fabricated into primal cuts and the weight of all primal cuts and of other commercial products was recorded ham, loin, picnic, Boston butt, belly, spare ribs, jowl, feet, neckbones, tail, lean trimmings, fat, and skin. Each commercial cut was subsequently dissected and separated into lean, fat, bone, and skin, and the weight of each component was recorded.

The total wholesale value (wholesale carcass valuel of each individual carcass was determined by multiplying the quantity of each trimmed wholesale cut and byproduct by average per-unit prices obtained from the National Provisioner Daily Market News Service (1988) Yellow Sheet following the recommendations of Hayenga et al. (1985). The Yellow Sheet prices were adjusted by adding the overages used by a cooperating packer in pricing its products to better reflect the quality of product actually sold on the wholesale market as well as transportation differentials. Killing and processing cost data were also obtained from this packer and were subtracted from the total wholesale value of the carcass to arrive at the net value of the carcass as raw material. One-half of the $(100 \%)$ lean trimmings were assumed to be sold on an $80 \%$ lean basis and onehalf were assumed to be sold on a $50 \%$ lean basis 5 . Carcass fat was added to lean trimmings to permit pricing the product with available wholesale price data. The remaining carcass fat was then converted to a lard equivalent using the appropriate yield factor (.7).

A second set of carcass values dean boneless carcass valuel was calculated assuming that the ham and loin were sold in highly trimmed, boneless form with the rest of the carcass sold on the wholesale market as described above. Again, the cooperating packer provided necessary price,

\footnotetext{
${ }^{4}$ The S-F-K Fat-O-Meater (S-F.K, Hvidovre, Denmark) was also used to measure backfat and longissimus muscle depth. However, this optical probe was not available during the early stages of the research and therefore measurements from the Fat-O-Meater were not available for all carcasses.

${ }^{5}$ Actually, 80 and $50 \%$ lean trimmings were adjusted to a 72 and $42 \%$ lean basis, respectively, to correspond with the products that are priced on the National Provisioner Yellow Sheet.

${ }^{8} \mathrm{Hayenga}$ et al. (1985) and Grisdale et al. (1984) also include a measure of muscling score based on a visual appraisal. The muscle score added little information to their results and it also makes little difference here. Hence the regressions reported here do not include a muscling score.
}

yield, and cost data. This second set of carcass values was used to examine the impact of carcass use on the predictive ability of the three techniques.

The models used to explain value included a measure of fatness or leanness and carcass weight. The EMSCAN model also controls for hot carcass temperature and carcass length. Carcass weight is important because prices for wholesale cuts vary according to weight of the cut. Heavy cuts receive discounts but these discounts do not vary directly with the weight of the cut; thus, a curvilinear relationship is expected. A quadratic weight variable was used following the method of Hayenga et al. (1985) ${ }^{B}$. The four models estimated were as follows:

$$
\begin{aligned}
\text { Value/100 kg }= & a_{0}+a_{1} \text { PROBEFD } \\
& +a_{2} \text { PROBEFD }^{2}+a_{3} \text { CARWT } \\
& +a_{4} \text { CARWT }^{2} \\
& +a_{5} \text { (PROBEFD.CARWT) } \\
& +a_{6} \text { PROBEMD }
\end{aligned}
$$

$$
\begin{aligned}
\text { Value/100 } \mathrm{kg}= & b_{0}+\mathrm{b}_{1} \text { ULTRAFD } \\
& +\mathrm{b}_{2} \text { ULTRAFD }^{2}+\mathrm{b}_{3} \text { CARWT } \\
& +\mathrm{b}_{4} \text { CARWT }^{2} \\
& +\mathrm{b}_{5} \text { (ULTRAFD.CARWT) } \\
& +\mathrm{b}_{6} \text { ULTRALEA }
\end{aligned}
$$

$$
\begin{aligned}
\text { Value } / 100 \mathrm{~kg}= & \mathrm{c}_{0}+\mathrm{c}_{1} \text { RULER }+\mathrm{c}_{2} \text { RULER }^{2} \\
& +\mathrm{c}_{3} \text { CARWT }+\mathrm{c}_{4} \text { CARWT }^{2} \\
& +\mathrm{c}_{5} \text { (RULER. CARWT) } \\
& +\mathrm{c}_{6} \text { DOTLEA }
\end{aligned}
$$

$$
\begin{aligned}
\text { Value/100 kg }= & d_{0}+d_{1} \text { EMH45 }+d_{2} \text { EMA75E } \\
& +d_{3} \text { CARWT }+d_{4} \text { CARWT }^{2} \\
& +d_{5} \text { CARTEMP } \\
& +d_{6} \text { CARLGTH }
\end{aligned}
$$

where Value/100 $\mathrm{kg}$ is the net carcass value (dollars) per 100 kilograms of carcass, PROBEFD is the backfat depth at the 11 th rib measured with the optical probe, PROBEMD is the depth of the longissimus muscle at the 11 th rib measured with the optical probe, CARWT is the weight of the hot carcass in kilograms, ULTRAFD is the backfat depth measured at the 10 th rib with the ultrasound scanner, ULTRALEA is the area of the longissimus muscle at the 10th rib measured with an ultrasound scanner, RULER is the backfat depth measured at the 10th rib with a ruler, DOTLEA is the area of the longissimus muscle at the 10th rib measured with a dot grid, EMH45 is the height of the EMSCAN conductivity index curve $45 \%$ of the distance from the curve's starting point to its peak, EMA75E is the area under the EMSCAN conductivity index curve from a point $3 / 4$ of the distance between the 
curve's origin and its peak to the curve's endpoint, CARTEMP is the temperature of the hot carcass, CARLGTH is the length of the carcass, and $a_{i}, b_{i}, c_{i}$, and $d_{i}$ are parameters.

Data were not used to specify the models. Models were specified based on the results of past research (Fahey et al., 1977; Grisdale et al., 1984; Hayenga et al., 1985; Forrest et al., 1989; Kuei et al., 1989; Orcutt et al., 1990). Insignificant variables were not deleted because the focus of the paper is testing hypotheses about the uniqueness of information provided by each technique, and deleting insignificant variables could bias the results. Because the data were not used to select the model, no out-of-sample evaluation is needed.

The next question was, What criteria should be used to compare the four models? Grisdale et al. (1984) concentrated their discussion on $R^{2}$ and stressed that their model had an $\mathrm{R}^{2}$ of .79 , which was higher than those of previous studies. But $\mathbf{R}^{2}$ is sample-dependent. In their study, Grisdale et al. (1984) selected a sample consisting of an equal number of barrows and gilts representing four distinctly different body types. The population of hogs used in the present study reflects a more normal distribution with fewer hogs in the extreme categories. For instance, the standard deviation of the hot carcass weight variable for the 185 carcasses used in the Grisdale et al. (1984) study was $12.3 \mathrm{~kg}$, compared to $6.1 \mathrm{~kg}$ for the 90 carcasses used in this sample. Therefore, we expected a substantially lower $\mathrm{R}^{2}$ with these data?.

Because $\mathrm{R}^{2}$ does not produce a test of statistical significance, we selected among the four models using non-nested hypotheses tests (David-

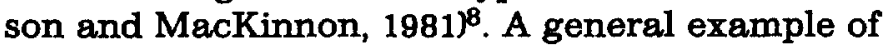
non-nested models is as follows:

H1: Model 1 is correct Model 1: $y_{i}=\sum_{i=1}^{n} \beta_{i} X_{i}+\varepsilon_{1 i}$
H2: Model 2 is correct Model 2: $y_{i}=\sum_{i=1}^{m} \gamma_{i} Z_{i}+\varepsilon_{2 i}$

where $y_{i}$ is the $i^{\text {th }}$ observation on the dependent variable, $X_{i}$ and $Z_{i}$ are vectors of observations on exogenous variables, $\beta_{i}$ and $\gamma_{i}$ are vectors of parameters to be estimated, and $\varepsilon_{1 i}$ and $\varepsilon_{2 i}$ are error terms. For the models to be non-nested, Model 1 must contain independent variables not in Model 2 and Model 2 must contain independent variables not in Model 1. Using non-nested tests (described below), both $\mathrm{H} 1$ and $\mathrm{H} 2$ may be rejected, or neither may be rejected. If neither is rejected, then both models contain the same information. If both are rejected, then both $X_{i}$ and $Z_{i}$ contain unique information that helps to predict $y_{i}$. The third possibility is more definitive: one hypothesis may be rejected and the other not. Here, the model not rejected would be chosen over the rejected model. The non-nested hypothesis tests will provide information about whether one of the four methods of predicting carcass value contains information that is not captured in the others.

Two types of non-nested tests are used: 1) the Wald test, which is valid in small and large samples, and 2) the J-test, which has larger asymptotic power than the Wald test, but is biased in small samples. The Wald test nests all four non-nested models in a more general model:

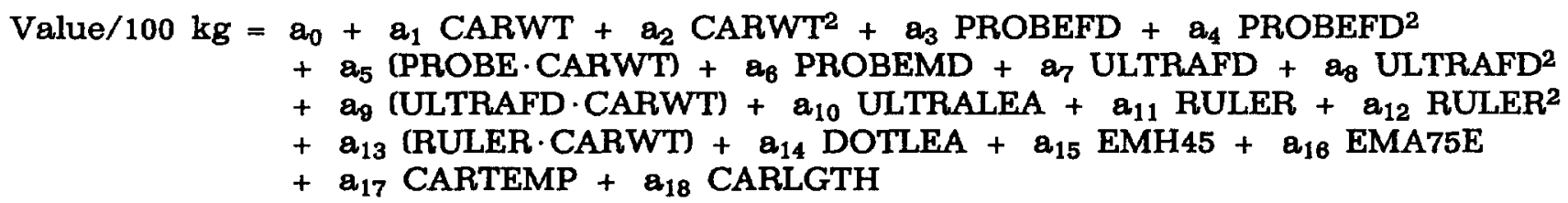

The following null hypotheses are then tested:

$$
\begin{aligned}
& \mathrm{H}_{1} \text { : Optical probe is correct } \mathrm{H}_{0}: a_{7}=0, a_{8}=0, a_{9}=0, a_{10}=0, a_{11}=0, a_{12}=0, a_{13}=0 \text {, } \\
& a_{14}=0, a_{15}=0, a_{16}=0, a_{17}=0, a_{18}=0 \text {. } \\
& \mathrm{H}_{2} \text { : Ultrasound is correct } \mathrm{H}_{0}: a_{3}=0, a_{4}=0, a_{5}=0, a_{6}=0, a_{11}=0, a_{12}=0, a_{13}=0 \text {, } \\
& a_{14}=0, a_{15}=0, a_{16}=0, a_{17}=0, a_{18}=0 \text {. } \\
& H_{3} \text { : Ruler is correct } H_{0}: a_{3}=0, a_{4}=0, a_{5}=0, a_{6}=0, a_{7}=0, a_{8}=0, a_{9}=0, a_{10} \\
& =0, a_{15}=0, a_{16}=0, a_{17}=0, a_{18}=0 \text {. }
\end{aligned}
$$

\footnotetext{
${ }^{7}$ Estimating the Grisdale et al. (1984) equation with these data gives an $R^{2}$ of .20. Siemens et al. (1989) used a similar approach and obtained results like those of Grisdale et al. (1984). The primary difference is the use of quadratic variables by Siemens ot al. (1989).
}

\footnotetext{
${ }^{8}$ Most statistical tests are nested because the model under the null hypotheses is a special case of the alternative. The models defined in Equations (1) to (4) are non-nested because none of the models is a special case of the others.
} 


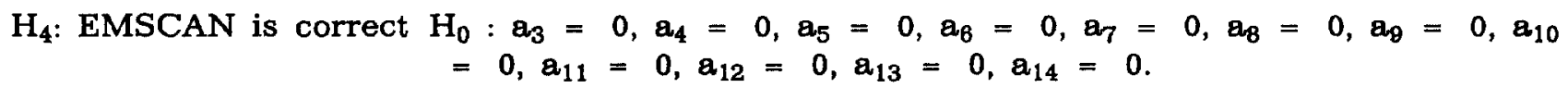

Here the null hypothesis, $\mathrm{H}_{1}$ : Optical probe is correct, should be interpreted as the null hypothesis that the other measurements provide no useful information beyond that provided by the optical probe.

The J-test for any of the four hypotheses is conducted by taking the predicted values from the other three equations and including them as regressors in the model under consideration. For example, to test $\mathrm{H}_{1}$ : Optical probe is correct, estimate the following:

$$
\begin{aligned}
\text { Value/100 kg }= & a_{0}+a_{1} \text { PROBEFD } \\
& +a_{2} \text { PROBEFD }^{2}+a_{3} \text { CARWT } \\
& +a_{4} \text { CARWT }^{2} \\
& +a_{5} \text { (PROBEFD CARWT) } \\
& +a_{6} \text { PROBEMD }+a_{7} \hat{V}_{2} \\
& +a_{8} \hat{V}_{3}+a_{9} \hat{\mathrm{V}}_{4}
\end{aligned}
$$

where $\hat{V}_{2}, \hat{V}_{3}$, and $\hat{V}_{4}$ are the predicted values from Equations [2], [3], and [4]. The null hypothesis tested is $a_{7}=0, a_{8}=0, a_{9}=0$. Tests of the other three hypotheses are conducted in a similar fashion.

\section{Results and Discussion}

Wholesale value regression estimates are presented in Table 2. Readings from all four devices provided information useful in explaining carcass value as evidenced by the significant parameter estimates on measures of fatness or leanness. The null hypothesis of no information from the technique (joint $F$-test of the non-intercept parameters) was rejected $(P<.001)$ in each equation. The EMSCAN equation gave the best fit, explaining $49.8 \%$ of the total variation in value $/ 100 \mathrm{~kg}$. Values of $\mathrm{R}^{2}$ for the ultrasound, ruler, and optical probe wholesale value $/ 100 \mathrm{~kg}$ equations were .46 , .41 , and .40, respectively. A corresponding $R^{2}$ for total value of the carcass would, of course, be higher. The regression $F$-statistic was larger than

\footnotetext{
${ }^{9}$ Weight discounts were compared using results from the Hayenga ot al. (1985) model (Equation 2) estimated with our 1988 data. Hayenga et al. (1985) reported an increasing premium for light carcasses less than $81.5 \mathrm{~kg}$ ) and an increasing discount for heavy carcasses (greater than $81.5 \mathrm{~kg}$ ) using 1981 price data. We find both light and heavy carcasses discounted relative to the base carcass in 1888, with the discounts for heavy animals approximately twice those reported by Hayenga et al. (1885).

${ }^{10}$ Note that many packers discount light and heavy animals using a discount schedule that is not linked to the Yellow Sheet. Such discounts are not reflected in these estimates.
}

the .05 critical value for each of the four equations.

The relationship between weight and value $/ 100$ $\mathrm{kg}$ in our model is more complex than that of previous work because of the inclusion of the fatness $\times$ weight interaction term. Ikerd and Cramer (1970) used a system of equations that specified the relationship between value, carcass weight, and backfat depth as a function of price differentials between light and heavy primal wholesale cuts. Hayenga (1971) estimated a singleequation ordinary least squares (OLS) model that expressed carcass value (per unit of live weight) as a function of slaughter weight, backfat depth at the last lumbar region, and dressing percentage. Green et al. (1973) estimated a model similar to the Ikerd and Cramer (1970) model using a random coefficients approach that had more desirable statistical properties than the estimation method used earlier. Grisdale et al. (1984) and Hayenga et al. (1985) extended the early work of Hayenga (1971) by specifying a nonlinear relationship between value and carcass weight. Siemens et al. (1989) used quadratic weight, backfat depth, and muscling variables to predict wholesale carcass value.

The earlier studies using linear models found a statistically significant, inverse relationship between carcass value and carcass weight. However, both Hayenga et al. (1985) and Siemens et al. (1989), using a single-equation OLS model with a quadratic carcass weight variable, found that the weight discount increased with carcass weight over the typical weight range of animals slaughtered $^{\theta}$. In this study, although several of the individual parameters relating carcass weight to value were not significant, the hypothesis of no weight effect (joint $F$-test of the weight parameters) was rejected at the .01 level in three of the four equations, the optical probe equation being the sole exception. In every case, the relationship between weight and value was concave (i.e., heavy carcasses were discounted and this discount increased with weight ${ }^{10}$ ).

The negative estimated parameter on the backfat variable in the optical probe, ultrasound, and ruler equations indicated the expected discount for fat animals. However, the lack of statistical significance on any of the second-order backfat parameters suggests that this discount is linear with backfat depth. This finding is consistent with previous research. Ikerd and Cramer (1970), Hayenga (1971), Grisdale et al. (1984), Hayenga et al. (1985), and Siemens et al. (1989) all found a statistically significant, inverse relationship between carcass value and backfat depth ${ }^{11}$. Addi- 
Table 2. Regression estimates of models explaining

wholesale value/100 kilograms of pork carcasses

\begin{tabular}{|c|c|c|c|c|}
\hline \multirow[b]{2}{*}{$\begin{array}{l}\text { Independent } \\
\text { variable }\end{array}$} & \multicolumn{4}{|c|}{ Measure of leanness/fatness } \\
\hline & $\begin{array}{c}\text { Optical } \\
\text { probe }\end{array}$ & Ultrasound & Ruler & EMSCAN \\
\hline Intercept & $\begin{array}{l}54.51 \\
(1.07)^{\mathrm{a}}\end{array}$ & $\begin{array}{l}-23.31 \\
(-.467)\end{array}$ & $\begin{array}{c}12.31 \\
(.244)\end{array}$ & $\begin{array}{l}9.20 \\
(.201)\end{array}$ \\
\hline Backfat & $\begin{array}{r}-10.42^{\dagger} \\
(-1.76)\end{array}$ & $\begin{array}{l}-7.86 \\
(-1.14)\end{array}$ & $\begin{array}{l}-10.98^{t} \\
(-1.78)\end{array}$ & - \\
\hline Backfat ${ }^{2}$ & $\begin{array}{c}.305 \\
(.646)\end{array}$ & $\begin{array}{c}.239 \\
(.321)\end{array}$ & $\begin{array}{c}-.181 \\
(-.373)\end{array}$ & - \\
\hline Carwt & $\begin{array}{c}2.05 \\
(1.56)\end{array}$ & $\begin{array}{l}3.87^{* *} \\
(3.12)\end{array}$ & $\begin{array}{c}3.07^{*} \\
(2.44)\end{array}$ & $\begin{array}{l}3.01 * * \\
(2.70)\end{array}$ \\
\hline Carwt $^{2}$ & $\begin{array}{c}-.014 t \\
(-1.67)\end{array}$ & $\begin{array}{l}-.026^{* *} \\
(-3.37)\end{array}$ & $\begin{array}{c}-.022 * * \\
(-2.84)\end{array}$ & $\begin{array}{l}-.022^{* *} \\
(-3.10)\end{array}$ \\
\hline Fatness $\cdot$ carwt & $\begin{array}{r}.081 \\
(1.03)\end{array}$ & $\begin{array}{c}.053 \\
(.683)\end{array}$ & $.139^{\dagger}$ & - \\
\hline Loin muscle & $\begin{array}{l}1.78 * * * \\
(3.77)\end{array}$ & $\begin{array}{l}.428 * \star \star \\
(5.18)\end{array}$ & $\begin{array}{l}.40 \theta^{* * *} \\
(4.35)\end{array}$ & - \\
\hline EMSCAN-H45 & - & - & - & $\begin{array}{r}.175 \\
(2.02)\end{array}$ \\
\hline EMSCAN-A75E & - & - & - & $\begin{array}{l}.004^{*} \\
(2.47)\end{array}$ \\
\hline Cartemp & - & - & - & $\begin{array}{l}-.778 * \\
(-2.63)\end{array}$ \\
\hline Carlgth & - & - & - & $\begin{array}{l}.284^{*} \\
(2.50)\end{array}$ \\
\hline $\begin{array}{l}\text { Regression } F \\
\mathrm{R}^{2}\end{array}$ & $\begin{array}{c}9.277^{* * *} \\
.4014\end{array}$ & $\begin{array}{c}11.858^{* * *} \\
.4615\end{array}$ & $\begin{array}{c}8.781 * * * \\
.4142\end{array}$ & $\begin{array}{c}13.697^{* * *} \\
.4975\end{array}$ \\
\hline SD & 2.473 & 2.345 & 2.446 & 2.266 \\
\hline
\end{tabular}

tional muscling is rewarded, as indicated by the positive parameters on the longissimus muscle variables. Also of interest is the estimated parameter on the fatness $\times$ weight interaction term, which is significant in the ruler equation. The positive sign indicates that the discount per centimeter of backfat declines as carcass weight increases-an intuitively appealing result.

The parameters on the EMSCAN measures of muscling, EMH45 and EMA75E, were significant and carried the expected positive signs. Carcass temperature was an important variable in the EMSCAN equation. However, this variable is not likely to be necessary in the industrial version of the EMSCAN equation because carcass temperature would be much more uniform in a production environment.

\footnotetext{
${ }^{11}$ The Hayenga et al. (1885) model (Equation 2) was estimated with our data to make a direct comparison of backfat differentials in 1981 and 1988. Hayenga et al (1985) report a backfat discount of $1.3 \%$ of carcass value per centimeter of backfat in 1981. Comparable figures using our 1888 data are $1.2 \%$ for the wholesale value model and $4.6 \%$ for the lean, boneless value model.
}

The two non-nested tests produced consistent results (Table 3). All the null hypotheses were rejected for both the Wald and the J-tests, implying that each technique for measuring carcass composition provides some unique information. Hence, none of the four methods contains all the information provided by the other three.

There are at least two reasons for the difference in information content of the four techniques even though three of the four measure backfat depth and lean muscle area (or depth) at a specific location. First, there is some difference in the location on the carcass where the readings were taken. Both the ruler reading and the ultrasound reading were taken at approximately the same location: $5 \mathrm{~cm}$ off the midline at the $10 \mathrm{th}$ rib. However, the optical probe reading is taken $7 \mathrm{~cm}$ off the midline between the 11 th and 12 th rib. Second, there is likely to be some difference in accuracy between the three backfat/longissimus muscle measurement techniques. The ruler should be the most accurate measure of backfat depth because identifying the precise line of demarcation separating lean and fat using ultra- 
Table 3. Test statistics for non-nested tests of four measures of carcass composition to explain wholesale value/100 kilograms of pork carcasses

\begin{tabular}{lcccc}
\hline \hline & \multicolumn{2}{c}{ Null hypothesis } \\
\cline { 2 - 5 } $\begin{array}{l}\text { Non-nested } \\
\text { test }\end{array}$ & $\begin{array}{c}\text { Optical probe } \\
\text { correct }\end{array}$ & $\begin{array}{c}\text { Ultresound } \\
\text { correct }\end{array}$ & $\begin{array}{c}\text { Ruler } \\
\text { correct }\end{array}$ & $\begin{array}{c}\text { EMSCAN } \\
\text { correct }\end{array}$ \\
\hline Wald & 4.0870 & 3.0823 & 3.8738 & 2.4810 \\
& {$[.0001]^{2}$} & {$[.0015]$} & {$[.0001]$} & {$[.0080]$} \\
$J$-test & 16.207 & 9.880 & 15.079 & 6.259 \\
& {$[.0001]$} & {$[.0001]$} & {$[.0001]$} & {$[.0008]$} \\
\hline
\end{tabular}

${ }^{\text {a}}$ Values in brackets are observed significance levels.

sound or the optical probe involves some judgment on the part of the operator. Likewise, the dot grid should be the most accurate measure of longissimus muscle area.

Because three of the techniques measure fatness and leanness at approximately the same location, pair-wise, non-nested tests were conducted to compare each technique against the three alternatives on an individual basis (i.e., probe against ultrasound, probe against ruler, probe against EMSCAN, etc.; Table 4). Results suggested that EMSCAN, the optical probe, and ultrasound provide unique information. However, all information available from the ruler measure was contained in the EMSCAN measure. In addition, based solely on information content one would be indifferent to the ruler and the optical probe. Although none of the four methods for determining composition dominated all others when considered jointly the similarity of the information provided by the ultrasound, the ruler, and the probe was shown by the pair-wise tests.

The above value models are based on the assumption that the carcass was to be sold on the wholesale primal market. As shown in Table 1, the variation in wholesale value per $100 \mathrm{~kg}$ is considerable, ranging from $\$ 118.63$ to $\$ 137.65$, with a mean of $\$ 127.69$ and a standard deviation of $\$ 3.94$. However, if the carcass were to be used to market lean, boneless products, carcass composition obviously becomes more important to the packer and the need for a system that links carcass price to carcass composition becomes more critical.

The second set of carcass values dean boneless carcass value) was used to examine this issue. The average value per $100 \mathrm{~kg}$ for a carcass marketed assuming the ham and loin were sold in lean, boneless form was $\$ 131.27$, ranging from $\$ 107.87$ to $\$ 153.92$ with a standard deviation of $\$ 7.71$ (Table 1). Estimated parameters for the four lean, boneless pricing models are presented in Table 5. In general, the estimates are consistent with those for the wholesale value model presented in Table 2. However, in every case the discount for fat or the premium for muscling was higher in the lean, boneless model than in the wholesale model. In addition, the $\mathrm{R}^{2}$ values for the lean, boneless models were much higher than those for the earlier models. The EMSCAN model explained more than $75 \%$ of the variation in lean, boneless carcass value.

The group non-nested tests for the lean, boneless equations provided results similar to those

Table 4. Test statistics for pair-wise, non-nested Wald tests of four measures of carcass composition to explain wholesale value/100 kilograms of pork carcasses

\begin{tabular}{lcccc}
\hline \hline & \multicolumn{4}{c}{ Comparison } \\
\cline { 2 - 5 } $\mathrm{H}_{0}$ & $\begin{array}{c}\text { Optical } \\
\text { probe }\end{array}$ & Ultrasound & Ruler & EMSCAN \\
\hline Optical probe is correct & - & 6.2454 & 2.3585 & 8.2762 \\
Ultrasound is correct & 3.634 & {$[.0002]$} & {$[.0605]$} & {$[.0001]$} \\
Ruxler is correct & {$[.0090]^{\mathrm{a}}$} & - & 1.1044 & 5.8795 \\
& 1.8873 & & {$[.3604]$} & {$[.0003]$} \\
EMSCAN is correct & {$[.1209]$} & {$[.0387$} & - & 6.1781 \\
& 3.7767 & 4.1668 & 2.4895 & {$[.0002]$} \\
& {$[.0073]$} & {$[.0041]$} & {$[.0498]$} & - \\
\hline
\end{tabular}

avalues in brackets are observed significance levels. 
Table 5. Regression estimates of models explaining lean, boneless value/100 kilograms of pork carcasses

\begin{tabular}{|c|c|c|c|c|}
\hline \multirow[b]{2}{*}{$\begin{array}{l}\text { Independent } \\
\text { variable }\end{array}$} & \multicolumn{4}{|c|}{ Measure of leanness/fatness } \\
\hline & $\begin{array}{c}\text { Optical } \\
\text { probe }\end{array}$ & Ultrasound & Ruler & EMSCAN \\
\hline Intercept & $\begin{array}{c}110.05 \\
(1.40)^{\mathrm{a}}\end{array}$ & $\begin{array}{c}-37.70 \\
(-.466)\end{array}$ & $\begin{array}{c}13.24 \\
(.181)\end{array}$ & $\begin{array}{l}55.30 \\
(.883)\end{array}$ \\
\hline Backfat & $\begin{array}{c}-20.15^{\star} \\
(-2.21)\end{array}$ & $\begin{array}{l}-13.65 \\
(-1.22)\end{array}$ & $\begin{array}{c}-18.07^{\star} \\
(-2.25)\end{array}$ & - \\
\hline Backfat ${ }^{2}$ & $\begin{array}{c}.305 \\
(.420)\end{array}$ & $\begin{array}{c}.380 \\
(.314)\end{array}$ & $\begin{array}{c}-.155 \\
(-.222)\end{array}$ & - \\
\hline Carwt & $\begin{array}{c}.852 \\
(.423)\end{array}$ & $\begin{array}{l}4.27^{*} \\
(2.12)\end{array}$ & $\begin{array}{l}3.05^{\dagger} \\
(1.77)\end{array}$ & $\begin{array}{c}1.81 \\
(1.25)\end{array}$ \\
\hline Carwt ${ }^{2}$ & $\begin{array}{l}-.008 \\
(-.450)\end{array}$ & ${ }^{-.027^{*}}$ & $\begin{array}{c}-.022^{*} \\
(-2.07)\end{array}$ & $\begin{array}{l}-.018^{\dagger} \\
(-1.86)\end{array}$ \\
\hline Backfat $\cdot$ carwt & $\begin{array}{r}.148 \\
(1.23)\end{array}$ & $\begin{array}{l}.080 \\
(.480)\end{array}$ & ${ }_{(1.89)}^{.193^{\dagger}}$ & - \\
\hline Loin muscle & $\begin{array}{l}2.82^{\star * *} \\
(4.04)\end{array}$ & ${ }^{.758 * * * *}$ & $\begin{array}{l}.849^{* \star \star *} \\
(6.58)\end{array}$ & - \\
\hline EMSCAN-H45 & - & - & - & $\begin{array}{l}.332^{* *} \\
(2.80)\end{array}$ \\
\hline EMSCAN-A75E & - & - & - & ${ }_{(5.00)}^{.011 * k *}$ \\
\hline Cartemp & - & - & - & $\begin{array}{l}-2.14 * \cdots \\
(-5.27)\end{array}$ \\
\hline Carlgth & - & - & - & $\begin{array}{l}.753 * * * \\
(4.85)\end{array}$ \\
\hline $\begin{array}{l}\text { Regression } F \\
\mathbf{R}^{2} \\
\mathrm{SD}\end{array}$ & $\begin{array}{l}23.78 \theta^{* * *} \\
.6321 \\
3.68\end{array}$ & $\begin{array}{l}23.576 * \cdots \\
.6302 \\
3.700\end{array}$ & $\begin{array}{c}34.044 * * \\
.7111 \\
3.271\end{array}$ & $\begin{array}{l}42.538 * * * \\
.7546 \\
3.014\end{array}$ \\
\hline
\end{tabular}

reported earlier: the null hypotheses were rejected in every instance for both the Wald test and the J-test (Table 6). However, the pair-wise tests suggested that the ruler was superior to the probe and the ultrasound techniques (i.e., we fail to reject the null hypothesis "ruler is correct" in the pair-wise tests; Table 7). Given the earlier results, which were inconclusive regarding the choice between ultrasound, the probe, and the ruler, this result suggested that use of the carcass will have an impact on the choice of carcass evaluation technique. Like the results for the wholesale value equations, the pair-wise test results for the lean, boneless equations suggested that EMSCAN provides information not provided by the other three techniques.

Despite the considerably higher predictive power of the EMSCAN equation for both the wholesale and lean, boneless value models, the non-nested test results suggested that techniques such as the optical probe, ultrasound, and the ruler do provide information beyond that con-

Table 6. Test statistics for non-nested tests of four measures of carcass composition to explain lean, boneless value/100 kilograms of pork carcasses

\begin{tabular}{lcccc}
\hline \hline & \multicolumn{4}{c}{ Null hypothesis } \\
\cline { 2 - 5 } $\begin{array}{l}\text { Non-nested } \\
\text { test }\end{array}$ & $\begin{array}{c}\text { Optical probe } \\
\text { correct }\end{array}$ & $\begin{array}{c}\text { Ultrasound } \\
\text { correct }\end{array}$ & $\begin{array}{c}\text { Ruler } \\
\text { correct }\end{array}$ & $\begin{array}{c}\text { EMSCAN } \\
\text { correct }\end{array}$ \\
\hline Wald & 10.884 & 11.0710 & 7.3568 & 5.357 \\
& {$\left[.00017^{a}\right.$} & {$[.00011$} & {$[.00011$} & {$[.0001]$} \\
J-test & 41.997 & 37.451 & 24.878 & 13.907 \\
& {$[.0001]$} & {$[.0001]$} & {$[.0001]$} & {$[.0001]$} \\
\hline
\end{tabular}

The values in brackets are observed significance levels. 
Table 7. Test statistics for pair-wise, non-nested Wald tests of four measures of carcass composition to explain lean, boneless value 100 kilograms of pork carcasses

\begin{tabular}{lcccc}
\hline \hline & \multicolumn{4}{c}{ Comparison } \\
\cline { 2 - 5 } $\mathrm{H}_{0}$ & $\begin{array}{c}\text { Optical } \\
\text { probe }\end{array}$ & Ultrasound & Ruler & EMSCAN \\
\hline Optical probe is correct & - & 10.0051 & 8.7876 & 25.5018 \\
& & {$[.0001]$} & {$[.0001]$} & {$[.0001]$} \\
Ultrasound is correct & 10.1586 & - & 7.3021 & 19.7428 \\
& {$[.0001]^{\mathrm{a}}$} & & {$[.0001]$} & {$[.0001]$} \\
Ruler is correct & 2.6631 & 1.3874 & - & 13.8655 \\
& {$[.0385]$} & {$[.2459]$} & & {$[.0001]$} \\
EMSCAN is correct & 10.4352 & 6.4585 & 8.8005 & - \\
& {$[.0001]$} & {$[.0002]$} & {$[.0001]$} & - \\
\hline
\end{tabular}

avalues in brackets are observed significance levels.

tained in the EMSCAN reading. Hence, packers may consider combining techniques to provide more accurate estimates of carcass value by using two (or more) unique sources of information. A revised model that incorporated readings from the EMSCAN device and the optical probe was estimated (Table 8). Residual standard deviations were lowered substantially through this combination of techniques $-\$ 2.12$ vs $\$ 2.27$ for the wholesale model and $\$ 2.51$ vs $\$ 3.01$ for the lean, boneless model. The EMSCAN/optical probe model explained $57 \%$ of the variation of wholesale value and $83 \%$ of the variation in lean, boneless value.

Making formal statistical comparisons of the EMSCAN/optical probe model against ultrasound and the ruler, the hypothesis "EMSCAN/optical probe is correct" is not rejected at the .05 level with the group non-nested test. In addition, the combination of techniques also was superior to the ultrasound or the ruler individually when the comparisons were made in pair-wise fashion. Such combinations of techniques merit additional investigation as a method to enluance the ability to predict carcass value.

Finally, the information provided by the technologies must be presented in a convenient, easily understandable format if it is to be used. A pork value grid was developed using the estimated wholesale value optical probe model because this technique is already in use in a number of plants (Table 9). Following earlier work by the National Pork Producers Council (1987), a base carcass in this grid carries $2.5 \mathrm{~cm}$ of backfat and weighs between 74 and $77 \mathrm{~kg}$. Premiums and discounts expressed as a percentage of base carcass value are shown for backfat depths from 1.5 to $5.5 \mathrm{~cm}$ and carcass weights from 62 to $97 \mathrm{~kg}$. Grid entries for light carcasses were adjusted according to the 1987 NPPC "Lean Guide to Pork Value" (National Pork Producers Council, 1987). Note that the optical probe wholesale value model contained a measure of longissimus muscle depth to adjust the estimated carcass value for the muscling of the animal. Therefore, each cell in the value grid was adjusted for the (estimated) longissimus muscle depth of an animal falling in that weight/ backfat class (i.e., the discount for a carcass with $2.0 \mathrm{~cm}$ of backfat and weighing $67 \mathrm{~kg}$ was calculated assuming the carcass has a loin muscle depth of $5.1 \mathrm{~cm}$ ). The determination of

Table 8. Regression estimates of models explaining value/100 kilograms of pork carcasses combining EMSCAN and optical probe measures

\begin{tabular}{|c|c|c|}
\hline \multirow[b]{2}{*}{$\begin{array}{l}\text { Independent } \\
\text { variable }\end{array}$} & \multicolumn{2}{|c|}{ Value/100 kg } \\
\hline & Wholesale & $\begin{array}{c}\text { Lean, } \\
\text { boneless }\end{array}$ \\
\hline Intercept & $\begin{array}{l}41.29 \\
(.828)^{\mathrm{a}}\end{array}$ & $\begin{array}{l}80.89 \\
(1.49)\end{array}$ \\
\hline Carwt & $\begin{array}{c}1.74^{\dagger} \\
(1.55)\end{array}$ & $\begin{array}{c}.621 \\
(.454)\end{array}$ \\
\hline Carwt ${ }^{2}$ & $\begin{array}{c}-.013^{\dagger} \\
(-1.82)\end{array}$ & $\begin{array}{l}-.008 \\
(-.894)\end{array}$ \\
\hline EMSCAN-H45 & $\begin{array}{r}.117 \\
(1.38)\end{array}$ & $\begin{array}{r}.165 \\
(1.61)\end{array}$ \\
\hline EMSCAN-A75E & $\begin{array}{c}.004^{*} \\
(2.37)\end{array}$ & $\frac{.009^{* \star *}}{(4.83)}$ \\
\hline Cartemp & $\begin{array}{c}-.706^{*} \\
(-2.42)\end{array}$ & $\begin{array}{l}-1.67 * * * \\
(-4.68)\end{array}$ \\
\hline Carigth & $\begin{array}{l}.384^{* * *} \\
(3.38)\end{array}$ & ${ }_{(5.66)}^{.803^{* * *}}$ \\
\hline Probe measure (backfat) & $\begin{array}{l}.324 \\
(.547)\end{array}$ & $\begin{array}{l}-1.64^{*} \\
(-2.28)\end{array}$ \\
\hline Probe measure doin muscle) & $\begin{array}{l}1.65 * \bullet * \\
(3.68)\end{array}$ & $\begin{array}{l}2.67^{* * *} \\
(4.88)\end{array}$ \\
\hline $\begin{array}{l}\text { Regression } F \\
\mathrm{R}^{2} \\
\mathrm{SD}\end{array}$ & $\begin{array}{c}13.462^{* * \star} \\
.5707 \\
2.120\end{array}$ & $\begin{array}{c}50.711^{* * *} \\
.833 \theta \\
2.513\end{array}$ \\
\hline
\end{tabular}


Table 9. Premiums and discounts as a percentage of base market price based on optical probe pricing modela

\begin{tabular}{|c|c|c|c|c|c|c|c|c|c|}
\hline \multirow{2}{*}{$\begin{array}{l}\text { Carcass } \\
\text { weight, kg }\end{array}$} & \multicolumn{9}{|c|}{ Backfat, cm } \\
\hline & 1.5 & 2.0 & 2.5 & 3.0 & 3.5 & 4.0 & 4.5 & 5.0 & 5.5 \\
\hline 62 to $65^{b}$ & $85.1^{\mathrm{C}}$ & 83.0 & 81.1 & 79.2 & 77.4 & 75.7 & 74.1 & 72.6 & 71.2 \\
\hline 66 to $6 \theta$ & 95.5 & 93.6 & 81.8 & 80.1 & 88.5 & 87.0 & 85.5 & 84.2 & 82.9 \\
\hline 70 to 73 & 100.7 & 99.0 & 97.4 & 95.8 & 94.4 & 93.0 & 81.8 & 80.6 & 89.5 \\
\hline 74 to 77 & 103.0 & 101.4 & 100.0 & 88.6 & 87.4 & 96.2 & 85.1 & 84.1 & 93.2 \\
\hline 78 to 81 & 103.1 & 101.7 & 100.4 & 89.2 & 88.2 & 87.1 & 96.2 & 85.4 & 84.6 \\
\hline 82 to 85 & 102.6 & 101.4 & 100.3 & 88.3 & 88.3 & 87.5 & 86.7 & 86.1 & 85.5 \\
\hline 86 to $8 \theta$ & 101.5 & 100.4 & 89.5 & 98.7 & 87.9 & 87.2 & 86.7 & 96.2 & 95.8 \\
\hline 80 to 83 & 98.7 & 98.9 & 98.1 & 97.5 & 86.9 & 86.4 & 86.0 & 85.7 & 95.4 \\
\hline 84 to 97 & 97.4 & 96.7 & 96.2 & 95.7 & 95.3 & 84.9 & 94.7 & 84.6 & 94.5 \\
\hline
\end{tabular}

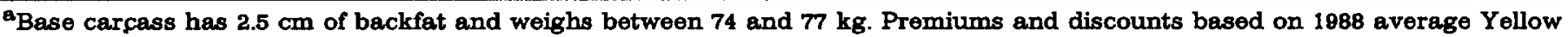
Sheet (adjusted) prices of trimmed, bone-in wholesale cuts.

biscounts for light carcasses were adjusted according to the 1987 NPPC "Lean Guide to Pork Value": $-14.0 \%$ for $62-$ to $65-\mathrm{kg}$ carcasses, $-5.5 \%$ for 68 - to $69 . \mathrm{kg}$ carcasses, and $-1.6 \%$ for 70 - to $73-\mathrm{kg}$ carcasses.

cPremiums and discounts shown are for animals with average loin muscle depth. Cell values would be adjusted for loin muscle depths above and below the mean loin muscle depth of a carcass in the cell. This adjustment would be $\pm 1.3 \%$ for the wholesale marketing system.

value is then a two-step procedure: first, the appropriate premium or discount is determined based on the weight of the carcass and the optical probe measure of backfat depth; then, the carcass value is adjusted for muscling if the depth of the longissimus muscle for the carcass is greater than or less than the average longissimus muscle depth for a carcass in that weight-backfat class.

The highest premium, $103.1 \%$ of base value, is for a carcass in the 78. to $81 \mathrm{~kg}$ range with $1.5 \mathrm{~cm}$ of backfat. Because processing costs are higher for very heavy animals, a set of discounts such as those developed by the NPPC for light carcasses may be required for the heavy weight classes
(Marberry, 1989). However, the optical probe value model already reflects such discounts to some extent because heavier cuts typically carry lower market prices.

When carcasses were valued assuming that the ham and loin would be sold in boneless, highly trimmed form, premiums and discounts became even more pronounced. Figure 1 presents the backfat discount for a carcass in the base weight range of 74 to $77 \mathrm{~kg}$. For a carcass in this weight class with $1.5 \mathrm{~cm}$ of backfat, the premium under this boneless value system is $106 \%$, and the corresponding premium for the wholesale value system is $102 \%$. Premiums and discounts for the

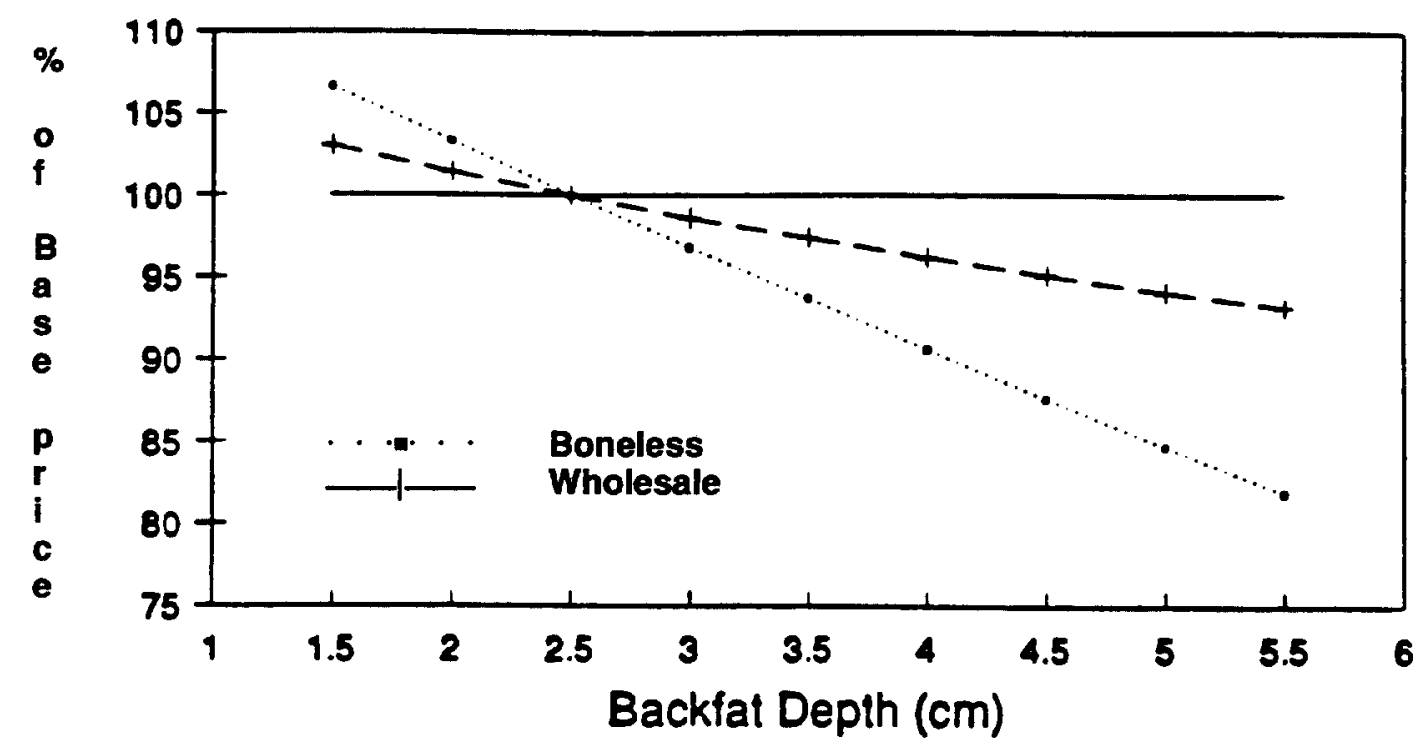

Figure 1. Backfat discounts for base carcass based on wholesale primal and lean, boneless carcass valuation (optical probe model). Plots show premiums and discounts for a 74- to 77-kg carcass with average loin muscle depth. 
wholesale value system were very similar to those in the 1987 revision of the "Lean Guide to Pork Value" (National Pork Producers Council, 1987). Incentives for the production of lean animals are much greater when the carcasses are valued on a lean, boneless basis. The expected use of the carcass is clearly important to consider when constructing a carcass-merit pricing system.

\section{Implications}

All four of the techniques considered provided information that significantly contributed to explaining carcass value. The EMSCAN device provided the most unique information. The combination of EMSCAN and optical probe readings was superior to the alternatives and suggested that such combinations merit additional research. Because each technique provides unique information in certain situations, other criteria, such as speed, reliability, and cost, may be more important in determining which of the techniques is adopted. Pricing premiums and discounts are affected by the use of the carcass. As packers continue to move toward leaner, boneless products, the value of a carcass-merit pricing system will increase.

\section{Literature Cited}

Davidson, R., and J. MacKinnon. 1981. Several tests for model specification in the presence of alternative hypotheses. Econometrica 49:781.

Dowell, A. A., and G. Engleman. 1949. Research into the problems involved in marketing slaughter livestock by carcass weight and grade. J. Farm Econ. 31:343.

Fahey, T. J., D. M. Schaefer, R. G. Kauffman, R. J. Epley, P. F. Gould, J. R. Romans, G. C. Smith, and D. G. Topel. 1877. A comparison of practical methods to estimate pork carcass composition. J. Anim. Sci. 44:8.

Forrest, J. C., C. H. Kuei, M. W. Orcutt, A. P. Schinckel, J. R. Stouffer, and M. D. Judge. 1989. A review of potential new methods of on-line pork carcass evaluation. J. Anim. Sci.
67:2164.

Groen, R., Z. A. Hassan, and S. R. Johnson. 1973. An alternative method for pricing pork carcasses. Can. J. Agric. Econ. 21: 1.

Grisdale, B., M. Hayenga, H. R. Cross, L. L. Christian, D. J. Meisinger, and R. G. Kauffman. 1884. Establishing practical guidelines for pricing market swine. J. Anim. Sci. 59: 883.

Hayenga, M. L. 1971. Hog pricing methods-their accuracy and equity. Am. J. Agric. Econ. 53:507.

Hayenga, M. L., B. S. Grisdale, R. G. Kauffman, H. R. Cross, and L. L. Christian. 1985. A carcass merit pricing system for the pork industry. Am. J. Agric. Econ. 67:315.

Inerd, J., and C. Cramer. 1870. Practical computer method for pricing pork carcasses and hogs. Am. J. Agric. Econ. 52: 242.

Kauffman, R. G. 1990. Leanvalue pricing system-pricing to stimulate change. Pork Strategies 2000: A Marketing and Technology Dynamics Symposium for the Pork Industry. Des Moines, IA.

Kempster, A., J. Chadwick, and D. Jones. 1985. An evaluation of the Hennessy Grading Probe and the SFK Fat-O-Meater for use in pig carcass classification and grading. Anim. Prod. 40:323.

Kuei, C. H., J. C. Forrest, M. W. Orcutt, M. D. Judge, and A. P. Schinckel. 1989. Electromagnetic scanning to estimate composition and weight of pork primal cuts and carcasses. 35th Int. Congr. Meat Sci. Technol. Vol. 1. p 249. Copenha. gen, Denmark.

Lewis, G. M. 1948. Roundtable on livestock marketing research-discussion. J. Farm Econ. 31:361.

Marberry, S. 1989. Hatfield goes for it. Hog Farm Management. February. p 14.

Miller, M. 1987. High yield scores: Do they tell you what you need to know? Pork '87. July. p 33.

National Pork Producers Council. 1887. Lean Guide to Pork Value. Des Moines, IA.

National Provisioner Daily Market News Service. 1988. The Yellow Sheet. Chicago, IL.

Orcutt, M. W., J. C. Forrest, M. D. Judge, A. P. Schinckel, and C. H. Kuei. 1890. Practical means for estimating pork carcass composition. J. Anim. Sci. 68:3987.

Quaife, T. 1987. Wooing the consumer: a consistent product gets eaten. Pork '87. August. $p 38$.

Siemens, A. L., T. B. Erickson, R. J. Lipsey, H. B. Hedrick, D. L. Seevers, R. O. Bates, F. L. Williams, Jr., and S. W. Yokley. 1989. Predictive equations for estimating lean cuts, fat standardized lean, chemical composition, bone and value of pork carcesses. J. Anim. Sci. 67:2033.

USDA. 1984. Grade and yield marketing of hogs. Packers and Stockyards Administration, Washington DC. 